\title{
Inserção digital e desigualdades na demanda por cultura no Brasil
}

\author{
Digital inclusion and inequalities of demand for culture in Brazil
}

\section{Abstract}

We intend to analyze the evolution of the concentration of cultural expenditures in the Brazilian Metropolitan Regions (MRs), based on the Brazilian Consumer Expenditure Survey of 2002-2003 and 2008-2009. The paper aims at understanding changes in consumption patterns in face of recent technological changes, focusing on inequalities between and inside Brazilian Metropolitan Regions. It was verified which items contributed to the increase (reduction) in the concentration of household expenditure on culture, through decomposition of the Gini coefficient according to the different items of cultural expenditures. The main findings were: significant increase in the consumption of new communication technologies; increased concentration of expenditure on outdoor cultural activities; the intensity of concentration is similar between the MRs, while within these regions income and education are the main factors influencing the propensity to consume.

\section{Keywords}

digital inclusion, cultural goods expenditures, desconcentration, classes of income, household expenditures, Brazilian Metropolitan Regions.

JEL Codes D12; D63; Z10.

\author{
Carla Cristina Rosa de Almeida (1) \\ João Policarpo Rodrigues Lima(2) \\ Maria Fernanda Freire Gatto (3) \\ (1) Universidade Federal de Mato Grosso \\ (2) Universidade Federal de Pernambuco \\ (3) Universidade Federal de Pernambuco
}

\section{Resumo}

Este artigo analisa a evolução da concentração dos gastos culturais nas Regiões Metropolitanas (RMs) brasileiras, com base nas Pesquisas de Orçamentos Familiares dos períodos 2002-2003 e 2008-2009. Pretende-se entender as alterações nas práticas de consumo na primeira década dos anos 2000 diante das mudanças tecnológicas recentes, com enfoque na evolução da desigualdade entre e dentro das RMs brasileiras. Para tanto, apresenta-se uma análise dos itens relacionados com o aumento (redução) da concentração dos gastos dentro do domicílio com cultura, através da decomposição do coeficiente de Gini segundo os diferentes itens de despesas culturais. Os principais resultados foram: aumento significativo no consumo de novas tecnologias de comunicação; aumento da concentração dos gastos fora do domicílio; intensidade da concentração semelhante entre as $R M s$, enquanto dentro das $R M s$ a renda e a educação são os principais fatores que influenciam a propensão a consumir.

\section{Palavras-chave}

inclusão digital, gastos com cultura, desconcentração, classes de renda, gastos domiciliares, Regiões Metropolitanas.

Códigos JEL D12; D63; Z10. 


\section{Introdução}

A baixa participação no orçamento familiar e a alta desigualdade dos gastos culturais, evidenciadas pela alta proporção de domicílios que não realizam gastos com cultura, não é característica única do Brasil e outros países subdesenvolvidos. A desigualdade de acesso à cultura tem sido amplamente discutida, com efeitos diretos nas políticas públicas, dada a importância da cultura na formação do indivíduo e como fator de transmissão de desigualdades sociais e educacionais, sobretudo, considerando a inércia das divisões sociais (Mantecón, 2009).

Os padrões de consumo podem ser utilizados para mensurar o bem-estar da sociedade e, mais recentemente, têm-se destacado estudos sobre a relação positiva entre felicidade reportada e atividades de lazer, entre elas, as culturais. Nesse sentido, Ateca-Amestoy et al. (2016) verificaram que o tipo de prática cultural importa, sendo que práticas de televisão e leitura têm impacto menor na felicidade, em contraposição à participação em eventos culturais.

Por sua vez, transformações recentes na economia brasileira têm afetado as decisões de consumo, incluindo as práticas culturais. Em primeiro lugar, pode-se citar a queda na desigualdade de renda após a década de 1990 (Hoffmann, 2006; 2010; Soares, 2006), ${ }^{1}$ que contribuiu para a redução na concentração das despesas familiares (Silveira Neto; Menezes, 2010). Em segundo lugar, tem-se a rápida expansão das novas tecnologias de informação e comunicação (TICs), que possibilita a inclusão digital ${ }^{2}$ e altera as preferências dos consumidores, provocando o deslocamento da demanda para esses bens e, consequentemente, aumentando os gastos culturais dentro do domicílio em detrimento do observado externamente (Earp, 2009; Earp; Paulani, 2014; Silva; Araújo; Souza, 2007). Fenômeno este que afeta as classes de renda baixa, média e alta, cujos perfis de consumo são diferenciados e por isso serão aqui analisados separadamente.

1 Contribuíram para a recente queda no índice de Gini: a) na década de 1990, a estabilização monetária e abertura comercial, que baratearam e promoveram maior acesso a produtos; e b) após 2002, o aumento do salário mínimo e os programas de transferências de renda.

2 A inclusão digital relaciona-se à capacidade de acessar informação e adequar-se às novas formas de organização dos processos produtivos, da circulação das mercadorias, do dinheiro e da organização da cultura decorrentes da expansão da internet (Bolaño; Reis, 2015). Além disso, entende-se que o acesso à informação "inclui diversas questões associadas à conectividade da rede, à disponibilidade de informações relevantes (...), à acessibilidade (...), ao valor acessível da informação (...)" (UNESCO, 2019, p. 27-28). 
Contudo, o acesso às TICs permanece altamente concentrado no país: em $2004,70 \%$ dos domicílios pertencentes ao $1 \%$ da classe de renda mais rica tinha acesso à internet, contra $0,64 \%$ dos domicílios pertencentes à faixa dos 40\% mais pobres (Mattos; Santos; Silva, 2011), dificultando o processo de inclusão digital, essencial para a democratização cultural. ${ }^{3}$ No entanto, não há investigações sobre as desigualdades de gastos culturais no Brasil e sua relação com o maior acesso às TICs. Mesmo na literatura internacional, os estudos são escassos, com destaque para o estudo de Fernández, Maldonado e Luque (2008) para a Espanha, que utilizaram metodologia semelhante à proposta neste artigo.

Nesse contexto, dadas as mencionadas transformações na economia brasileira, tem-se por hipótese que, nos anos 2000, houve alteração nas preferências - devido às novas formas disponíveis de entretenimento bem como houve redução na concentração dos gastos culturais, a favor das famílias de menor renda. Portanto, espera-se contribuir para aprofundar o conhecimento acerca das mudanças no padrão de consumo de bens culturais, bem como nas disparidades persistentes entre as diferentes classes.

Assim, tem-se como objetivo analisar a evolução dos gastos culturais domiciliares nos anos 2000 nas principais RMs brasileiras, ${ }^{4}$ com base na Pesquisa de Orçamentos Familiares - (POFs) de 2002-2003 e 2008-2009. Para tanto, verificou-se quais itens contribuíram para o aumento (redução) da concentração dos gastos dentro dos domicílios com cultura, através da decomposição do coeficiente de Gini segundo os diferentes itens de despesas culturais.

O trabalho divide-se em cinco seções. Na seção 2, traz-se uma revisão de literatura acerca dos aspectos relacionados às desigualdades de consumo cultural, com breves comentários sobre as questões das TICs. Na seção 3, explicita-se sobre os dados e a medidas de desigualdade utilizadas nas análises. Na seção 4, têm-se os resultados, particularmente a análise das

3 A ideia de democratização cultural extrapola a facilitação do acesso à cultura a partir da oferta de equipamentos culturais. Botelho (2003, p. 3) enumera algumas questões que devem ser consideradas: a) necessidade de enfocar na formação de capital cultural - no sentido de Bourdieu - cujos resultados levam entre duas e três gerações; b) promover o acesso aos meios de comunicação eletrônicos; c) aceitar que existe uma diversidade de públicos "(...) com respostas diferentes conforme localização espacial, faixa etária, condição de classe, história familiar, bagagem cultural" e, portanto, as políticas devem deixar "de se apoiar em premissas duvidosas, quase sempre não explicitadas, tais como 'só a cultura erudita, valor sacralizado, merece ser difundida'".

4 Regiões Metropolitanas de Belém, Fortaleza, Recife, Salvador, Belo Horizonte, Rio de Janeiro, São Paulo, Curitiba e Porto Alegre. 
despesas de consumo segundo itens de despesa e sua relação com renda e educação, além da evolução da concentração dos gastos culturais nas RMs. Por fim, na seção 5, têm-se as conclusões.

\section{Revisão de literatura}

O setor cultural abrange atividades representadas pelas artes, produção editorial, audiovisual, fonográfica, entre outros segmentos culturais, que têm assumido relevância na geração de emprego e renda, ao mesmo tempo que têm promovido novos formatos para seu consumo, tendo em vista os impactos advindos das tecnologias. Os bens culturais diferenciam-se dos tradicionais, por não possuírem muitas vezes classificação objetiva e universal, e por assemelharem-se, em alguns momentos, a bens não exclusivos e não rivais, como é o caso de apresentações públicas. Outra diferenciação é o caráter de originalidade e variedade, o que traz incerteza em relação à sua aceitação pelo mercado (Benhamou, 2007).

Por sua vez, o consumo cultural é dotado de especificidades decorrentes não somente das mencionadas características econômicas dos bens culturais, mas também de seus significados simbólicos, como reafirmação de identidade nacional ou regional. Assim, além do papel em âmbito de entretenimento, estético e/ou econômico, o acesso à cultura é importante ferramenta para o pleno desenvolvimento de capacidades e expressões que proporciona aos diferentes grupos (Mantecón, 2009).

Como fator de distinção social, há fortes evidências de que o consumo cultural repete a inércia das divisões sociais: as preferências por determinados tipos de bens culturais não ocorrem de forma natural (sensibilidade inata). Ao contrário, refletem o fato de os indivíduos pertencerem a um grupo social que valoriza determinados tipos de atividades culturais (status), sobretudo no caso do consumo da denominada "alta cultura" (cultura erudita). Dessa maneira, dado que as relações sociais e educativas dos agentes são responsáveis pela formação do "capital cultural" dos indivíduos - no sentido de Bourdieu ${ }^{5}$ - os "gostos" reproduzem as demais desigualdades sociais (Moraes, 2010).

5 Bourdieu conduziu estudos relevantes sobre as relações entre capital cultural e consumo cultural na França nas décadas de 1960 e 1970, publicados no trabalho Distinction: A Social Critique of the Judgement of Taste, em 1979. 
Nesse sentido, Ateca-Amestoy (2009, p. 98) analisou o comportamento de diferentes subpopulações quanto à participação em atividades culturais, concluindo que o nível de capital humano - educação formal e educação específica em artes - afeta a probabilidade de o indivíduo pertencer ou não ao grupo que nunca frequenta essas atividades. O trabalho seminal de Stigler e Becker (1977) já demonstrava que as preferências por bens culturais são influenciadas pelas experiências prévias dos indivíduos.

Na mesma direção, Machado et al. (2017, p. 35) afirmam que "os baixos níveis de consumo de cultura no Brasil são possivelmente mais relacionados à ausência de hábito que à ausência de tempo ou de recursos monetários". Em geral, diversos fatores sociodemográficos influenciam tais decisões, e é importante ressaltar que todos os estudos consultados encontraram evidências acerca da renda e da educação como positivamente correlacionadas com qualquer tipo de consumo cultural (Ateca-Amestoy, 2008; Ringstad, Loyland, 2006; Muñiz; Rodriguez; Suárez, 2017; Machado; Menezes; Diniz, 2011; Paglioto; Machado, 2012).

Especificamente acerca da desigualdade do consumo cultural e suas causas, os estudos mostram que esse contexto é presente tanto em países desenvolvidos quanto nos países em desenvolvimento. Na Europa, Benhamou (2007) observou altas desigualdades de consumo, sobretudo quando se trata das práticas coletivas e domésticas e, ainda mais acentuadas, quando diz respeito à "alta cultura". No México, Canclini (1999) e Mantecón (2009) procuraram entender a falta de interesse das camadas populares pela cultura erudita, destacando as barreiras decorrentes do capital cultural como impeditivas do consumo, criando o que Mantecón denominou de "não públicos da cultura", isto é, aqueles que sentem que não são eleitos para esses tipos de atividades.

No Brasil, vários estudos demonstraram que os gastos com bens e serviços culturais são concentrados por classe econômica, nível educacional e localização geográfica (Alves; Souza, 2012; Earp; Paulani, 2014; Silva; Araújo; Souza, 2007). Os bens culturais que exigem maior capacidade intelectual, por exemplo, restringem-se às famílias de renda mais alta e/ou com maior escolaridade (Silva; Araújo; Souza, 2007). Em complemento, pesquisas acerca dos hábitos culturais de diversas cidades do país, em geral, têm como resultado comum o alto número de indivíduos que nunca participaram de atividades eruditas, ainda que gratuitas, em comparação às práticas domésticas e populares (Leiva, 2014; Porto Alegre, 2015). 
A baixa participação em eventos gratuitos dessa natureza mostra que os fatores monetários não explicam, por si só, a existência dos "não públicos da cultura'" em conformidade ao exposto por Mantecón (2009).

No que tange à análise da concentração a partir de medidas de desigualdade, são escassos os estudos aplicados designadamente ao caso dos bens e serviços culturais. Entre estes, Fernández, Maldonado e Luque (2008), através dos dados da Encuesta Continua de Presupuestos Familiares, ${ }^{6}$ observaram que $38 \%$ das famílias espanholas não adquiriram livros, vídeos, televisores ou realizaram idas a cinema, teatros e museus. Também verificaram alta concentração nos gastos: para a maioria dos itens de despesa cultural e de lazer os valores dos coeficientes de Gini foram acima de 0,8.

No Brasil, não há estudos específicos sobre desigualdades dos gastos culturais. Porém, Silveira Neto e Menezes (2010), a partir de dados da POF 1996-1997 e 2002-2003, mostraram que o coeficiente de Gini do consumo total apresentou ligeira redução (de 0,527 para 0,515 ) nas principais $R M s$, com concomitante melhora na distribuição desses gastos, decorrente principalmente da maior participação no consumo pelas parcelas de população mais pobres. Os autores observaram também que recreação e cultura se encontram entre os itens de consumo que contribuíram para a redução desse coeficiente, com elevação da participação no consumo total e redução no coeficiente de Gini de 0,629 para 0,617.

Conforme já mencionado, espera-se que no período entre as POFs 20022003 e 2008-2009 tenha ocorrido redução na concentração dos gastos e alteração nas práticas culturais. Earp e Paulani (2014) atribuem as mudanças nos gostos por bens culturais a três fatores recentes: a) o aumento da renda - aumento do poder de compra devido ao Plano Real e a abertura comercial (barateamento dos bens de consumo duráveis) nos anos de 1990, bem como distribuição de renda e aumento do crédito pessoal nos anos 2000 - que acarretaram mudança no padrão de consumo a favor dos bens duráveis $^{7}$; b) mudança no espaço público de sociabilidade, com destaque para interação virtual, e c) causas específicas dos mercados que ocasionaram a ascensão de produtos substitutos. Em todos os casos, há um fator comum:

6 Os autores analisaram os gastos das famílias espanholas, que representavam quase $8 \%$ dos gastos totais em 2003. Cabe ressaltar que consideram uma cesta mais abrangente do que a delimitada neste artigo.

7 Entre esses, os equipamentos culturais privados, tais como televisores, DVDs, microcomputadores etc. 
o "deslocamento (...) para um novo suporte do bem cultural - algum meio eletrônico de preço relativamente mais baixo" (Earp; Paulani, 2014, p. 479).

Dessa forma, acentuou-se a substituição do uso do tempo livre para lazer em espaço público para privado, com maior uso desse tempo para novas atividades, tais como interação virtual (redes sociais), consumo audiovisual e internet; reduzindo ainda o tempo disponibilizado para consumo de livros e idas aos cinemas. Concomitantemente, discute-se o quão eficiente têm sido as políticas públicas recentes em prol da democratização cultural e inclusão digital. Alguns estudos apontam para a necessidade de se extrapolar a política isolada de facilitação ao acesso a determinados bens culturais (Canclini, 1999; Botelho, 2003; Mantecón, 2009) e às TICs (Bolaño; Reis, 2015), dado que a exclusão cultural e digital resulta, também, de desigualdades de renda e escolaridade.

Nesse contexto, o papel das novas TICs para a democratização cultural também tem sido debatido: por um lado, o acesso aumenta as possibilidades de escolhas entre as diferentes ofertas, por outro, é muito difícil inferir acerca do conteúdo que está sendo acessado. Segundo Mattos, Santos, Silva (2011, p. 19),

Em país de nivel de renda baixo e elevada concentração da renda e da riqueza, esse aspecto desfavorável gerado pela acelerada expansão tecnológica se amplifica, pois os mecanismos de exclusão de acesso às TICs pela renda se sobrepõem aos já graves problemas sociais enfrentados pelos cidadãos, a saber: baixa qualidade da Educação, o que permite baixa capacidade cognitiva à população em geral; baixo padrão de consumo; dificuldade de acesso à cultura e ao conhecimento científico. Nem mesmo a existência e a inegável proliferação de políticas públicas especificamente voltadas à expansão da inclusão digital parecem dar conta dos desafios que se sobrepõem em sociedades profundamente desiguais como a brasileira.

Com base nesse contexto é que se pretende entender as alterações nas práticas de consumo na primeira década dos anos 2000 diante das mudanças tecnológicas recentes, com enfoque na evolução da desigualdade nas RMs brasileiras.

\section{Estratégia empírica}

\subsection{Delimitação conceitual e espacial}

O estudo dos bens culturais caracteriza-se por bases de dados que não 
se encontram uniformizadas, dificultando a padronização das definições. Neste artigo, classificaram-se os gastos domiciliares ${ }^{8}$ com bens e serviços artísticos culturais quanto ao tipo de bem/serviço - direto ou indireto - e quanto ao local de dispêndio - se dentro ou fora do domicílio. Tem-se a seguinte classificação: a) gastos diretos fora do domicílio: espetáculos ao vivo e artes (teatros, museus, circo, espetáculos de dança); cinema; b) gastos diretos no domicílio: vídeo (artigos e assinatura de TV), fonografia, fotografia, leitura e artesanato, decoração ou artes plásticas; c) gastos indiretos ou complementares no domicílio: cursos de artes, instrumentos e acessórios musicais, informática (artigos e assinatura de internet), e d) gastos indiretos ou complementares fora do domicílio: outras festas e saídas (boates, parques, zoológicos, entre outros). ${ }^{9}$

Quanto à delimitação espacial, abrangeram-se as nove principais RMs do país: Belém, Fortaleza, Recife, Salvador, Belo Horizonte, Rio de Janeiro, São Paulo, Curitiba e Porto Alegre, no intuito de reduzir as heterogeneidades que poderiam afetar o consumo e que estariam vinculadas ao tamanho das cidades. ${ }^{10}$

\subsection{Dados}

As análises basearam-se nos microdados da POF 2002-2003 e da POF 20082009, realizadas pelo IBGE e principal base de dados com informações sobre gastos domiciliares monetários e não monetários no país. Os valores monetários da POF 2002-2003, que originalmente referem-se a janeiro de 2003, foram inflacionados pelo IPCA para janeiro de 2009 a fim de igualá-los ao ponto de deflacionamento da POF 2008-09 (IBGE, 2010). ${ }^{11}$

Devido à importância da variável renda e em consonância com o objetivo principal da pesquisa, optou-se por categorizar os domicílios conforme sua renda per capita, utilizando o critério SAE (2012), no qual a classe média apresenta renda per capita mensal entre $\mathrm{R} \$ 383,94$ e $\mathrm{R} \$ 1.392,40 .{ }^{12}$ As classes

\footnotetext{
8 Os microdados foram extraídos com as despesas anualizadas e agrupadas por domicílio.

9 Em conformidade com o estudo de Diniz e Machado (2011).

10 A expansão da análise para as outras RMs foi impossibilitada porque as selecionadas são as únicas identificadas na POF.

11 No período, registrou-se inflação de 39,367\%.

12 Deflacionados para valores de janeiro de 2009
} 
baixa e alta são compostas pelas famílias com per capita, respectivamente, abaixo e acima dos limites inferior e superior à média.

Foram descartados da amostra os domicílios que apresentaram os seguintes problemas: renda igual a zero; não declararam informações sociodemográficas; despesas iguais a zero para todos os tipos de bens; chefes menores de 18 anos e chefes com cônjuges menores de 14 anos. Ao final, obteve-se uma amostra de 5.932 domicílios em 2002-2003 e 7.327 em 2008-2009. Por se tratar de uma amostra complexa, fez-se necessário utilizar os pesos amostrais e expandir os valores para a população.

A estratégia empírica enfocou dois campos de análises: as principais mudanças em termos de bens e serviços consumidos no período pelo total de domicílios das RMs, relacionando sua relação com as novas TICs, bem como as diferenças nos padrões de consumo tanto entre as classes de renda - segundo itens consumidos e grau de concentração - quanto intraclasse -, com destaque para a diferença entre graus de escolaridade. Cabe ressaltar que a análise sobre concentração dos gastos culturais foi auferida através do índice de Gini e da decomposição dos gastos no período analisado, cuja metodologia é explicitada a seguir.

\subsection{Medidas de desigualdade ${ }^{13}$}

Os gastos culturais familiares foram analisados a partir do coeficiente de Gini. Supondo que o gasto com consumo de cultura está ordenado de forma crescente entre as famílias, o coeficiente de Gini pode ser obtido a partir da Equação 1.

$$
G=1-2 \beta
$$

onde $\beta$ é a área entre a curva de Lorenz e ao eixo das abcissas. ${ }^{14}$ De maneira análoga, é possível calcular o índice de Gini para cada uma das fontes de despesa $\left(G_{h}\right)$.

13 Essa subseção é baseada em Hoffmann (2006; 2010), Soares (2006) e Silveira Neto e Menezes (2010).

14 A curva de Lorenz é o gráfico de dispersão entre a proporção acumulada dos domicílios e a proporção acumulada dos gastos familiares per capitas com cultura. 
Assim, calculou-se o índice de Gini para as duas pesquisas da POF, tanto para os gastos agregados com cultura quanto para cada uma das fontes de despesas $h$. As estimações foram realizadas para o conjunto de observações do Brasil metropolitano por classe de renda.

Com o intuito de verificar a contribuição dos diversos itens de despesa cultural na variação do índice de Gini entre os dois períodos estudados, realizou-se a decomposição do coeficiente de Gini. O coeficiente de Gini pode ser decomposto em duas partes: a) coeficiente de concentração do item de despesa $h$ em relação à despesa total, representado por $C_{h}{ }^{15}$, e b) peso/participação da despesa $h$ na despesa total, representado por $S_{h}$. Assim, o coeficiente de Gini pode ser expresso por:

$$
G=\Sigma_{h} C_{h} S_{h}
$$

Para obter $C_{h}$ e $S_{h}$, realizou-se a decomposição do índice de Gini por fonte de despesa, separadamente, para os dois períodos em análise - 2002-2003 e 2008-2009. As estimações foram realizadas no pacote DASP, a partir do procedimento apresentado em Rao (1969). Fez-se uso dos pesos amostrais (sampling weight), e as estimativas de variância foram obtidas pelo método de linearização.

O procedimento pode ser realizado para apenas um período - e simular como determinado item de dispêndio afetaria a concentração dos gastos totais - ou para analisar como as diferentes fontes de despesas culturais contribuíram para a variação do índice de Gini entre dois períodos, como é o caso deste estudo. Dessa forma, utilizaram-se os procedimentos adotados para análises da evolução da concentração da renda familiar per capita em Soares (2006) e Hoffmann (2006; 2010), e para as despesas totais e as despesas com consumo, em Silveira Neto e Menezes (2010).

Conforme Hoffmann (2006), existe mais de uma maneira para calcular a variação do coeficiente que chega a resultados similares. Porém, Hoffmann e os demais autores mencionados sugerem o uso de uma combinação das formas possíveis, chegando-se a uma equação média da variação total do Gini:

15 A forma de calcular o índice de concentração é análoga à de Gini, com a diferença de que as variáveis de interesse não estão em ordem ascendente: para calcular o coeficiente de concentração de qualquer uma das fontes de despesas $h$, mantém-se o ordenamento pelos gastos totais em cultura. 


$$
\Delta G=\sum_{h}\left[\left(C^{*}{ }_{h}-G^{*} .\right) \Delta S_{h}+\left(S^{*}{ }_{h} \cdot \Delta C_{h}\right)\right]
$$

onde $C^{*}{ }_{h}, S^{*}{ }_{h}, G^{*}$ são, respectivamente, as médias de $C_{h}, S_{h}$, $G$ entre os dois períodos, enquanto $\Delta C_{h}, \Delta S_{h}$ e $\Delta G$ são suas variações.

A partir da Equação 3, é possível decompor o coeficiente de Gini em Efeito Participação (EP) e Efeito Concentração (EC) para cada cesta de bens e serviços, obtendo a contribuição da parcela da fonte de gasto $h$ na variação total do índice de Gini dos gastos culturais. A soma dos efeitos é igual ao Efeito Total (ET), obtido pela Equação 4.

$$
\left.E T=(\Delta G)_{h}=\left(C^{*}{ }_{h}-G^{*}\right) \cdot \Delta S_{h}+S^{*}{ }_{h} \cdot \Delta C_{h}\right)
$$

O EP representa o quanto a variação do coeficiente de Gini ocorreu devido à mudança do peso da fonte de gasto $h$ no total dos gastos com cultura. Por sua vez, o $E C$ significa o quanto a variação do coeficiente de Gini ocorreu em função da alteração da concentração da fonte de gasto $h$ entre os indivíduos, conforme Equações 5, 6 e 7:

a) Efeito Participação $\rightarrow E P_{(h)}=\left(C^{*}{ }_{h}-G^{*}\right) \cdot \Delta S_{h}$

b) Efeito Contribuição $\rightarrow E C_{(h)}=S^{*}{ }_{h} \cdot \Delta C_{h}$

$$
\text { c) } E T \text { (efeito total }) \rightarrow E T_{(h)}=E P_{(h)}+E C_{(h)}=(\Delta G)_{h}{ }^{16}
$$

Em geral, "o aumento da participação de uma parcela do gasto que apresenta um nível de concentração menor (maior) do que aquele verificado para o gasto total contribui para diminuição (aumento) da desigualdade", enquanto o "(...) efeito concentração total mostra o impacto de variações nos níveis de concentração das diferentes parcelas ou fontes de gasto na variação do nível de desigualdade do gasto total" (Silveira Neto; Menezes, 2010, p. 355). 


\section{Gastos culturais nas RMs brasileiras e inclusão digi- tal: evidências a partir das POFs 2002-2003 e 2008- 2009}

\subsection{Despesas de consumo por itens de bens e serviços culturais}

O gasto médio familiar per capita nas RMs passou de $\mathrm{R} \$ 40,94$ ao mês em 2002-2003 para R \$ 46,94 em 2008-2009. A discriminação por item de despesa, como demonstrado na Tabela 1 , sugere que o aumento no gasto domiciliar decorreu da elevação dos gastos indiretos, cuja participação no montante total variou de $35,24 \%$ para $50,62 \%$. Tal resultado deve-se à difusão dos gastos com informática entre as famílias, visto que os indicadores dos demais itens de consumo indiretos - cursos de artes, instrumentos musicais e outras saídas - praticamente não se alteraram. Houve elevação da participação relativa dos gastos com informática de 19,21\% em 2002-2003 para 39,09\% em 2008-2009, com destaque para os serviços de internet, cujo gasto per capita domiciliar mensal passou de $\mathrm{R} \$ 1,30$ ( $2,99 \%$ do total) para $\mathrm{R} \$ 11,48(25,27 \%)$, além do aumento na proporção de domicílios que declararam gastos nesse item.

Como esperado, as mudanças tecnológicas afetaram as prioridades dos indivíduos: a queda dos gastos diretos, tais como cinema, som e leitura, pode estar relacionada com a difusão desses conteúdos pela internet e o decorrente direcionamento das preferências pelas tecnologias digitais. Esse movimento já vinha ocorrendo desde os anos de 1990, como mostrado em Alves e Souza (2012), Earp (2009), Earp e Paulani (2014) e Silva, Araújo e Souza (2007).

A Figura 1 expressa o crescimento do consumo e do acesso às tecnologias digitais. $O$ percentual de domicílios com existência de microcomputador com acesso à internet passou de 11,42\% em 2003 para 27,38\% em 2009 , enquanto o acesso a telefonia elevou-se de $61,94 \%$ para $84,5 \%$ dos domicílios. Destacam-se os telefones celulares, presentes em $41,08 \%$ das casas, o que representa 173,9 milhões de aparelhos em 2009, contra 43 milhões em 2003. Por sua vez, o número de serviços de assinatura de televisão dobrou no período, de 3,6 milhões para 7,5 milhões. Tendo em vista que o gasto familiar médio per capita não se alterou, supõe-se que a difusão pode ter ocorrido paralelamente à redução nos preços das assinaturas, movimento este associado à busca de melhor posicionamento no mercado 
e à necessidade de ampliação da base de clientes por parte das operadoras (Rappa; Maranhão; Reis; Leandro, 2016).

Tabela 1 Despesas culturais domiciliares médias mensais per capita conforme itens de despesa cultural segundo POFs 2002-2003 e 2008-2009 - RMs

\begin{tabular}{|c|c|c|c|c|c|c|}
\hline \multirow[t]{2}{*}{ Despesa cultural } & \multicolumn{3}{|r|}{ 2002-2003 } & \multicolumn{3}{|r|}{$2008-2009$} \\
\hline & 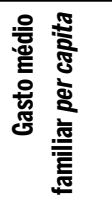 & 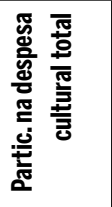 & 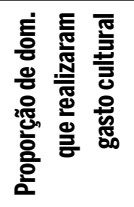 & 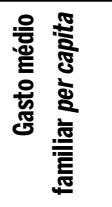 & 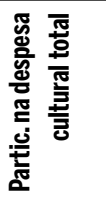 & 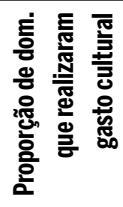 \\
\hline Total & $\mathrm{R} \$ 40,94$ & $100,00 \%$ & $73,47 \%$ & $\mathrm{R} \$ 46,94$ & $100,00 \%$ & $74,27 \%$ \\
\hline Direto & $\mathrm{R} \$ 26,31$ & $64,92 \%$ & $68,71 \%$ & $\mathrm{R} \$ 24,06$ & $49,38 \%$ & $67,25 \%$ \\
\hline Audiovisual & $\mathrm{R} \$ 19,39$ & $48,74 \%$ & $59,49 \%$ & $\mathrm{R} \$ 17,29$ & $36,79 \%$ & $58,48 \%$ \\
\hline Cinema & $\mathrm{R} \$ 2,32$ & $5,55 \%$ & $16,45 \%$ & $\mathrm{R} \$ 1,82$ & $3,94 \%$ & $13,80 \%$ \\
\hline Vídeo & $\mathrm{R} \$ 10,33$ & $25,45 \%$ & $32,51 \%$ & $\mathrm{R} \$ 11,46$ & $24,24 \%$ & $40,29 \%$ \\
\hline Artigos de vídeo & $\mathrm{R} \$ 6,15$ & $15,76 \%$ & $26,88 \%$ & $\mathrm{R} \$ 6,97$ & $15,19 \%$ & $34,64 \%$ \\
\hline Serv.TV & $\mathrm{R} \$ 4,19$ & $9,69 \%$ & $9,03 \%$ & $\mathrm{R} \$ 4,49$ & $9,09 \%$ & $9,97 \%$ \\
\hline Som & $\mathrm{R} \$ 6,72$ & $17,75 \%$ & $41,31 \%$ & $\mathrm{R} \$ 3,33$ & $7,04 \%$ & $28,97 \%$ \\
\hline Foto & $\mathrm{R} \$ 0,01$ & $0,04 \%$ & $0,13 \%$ & $\mathrm{R} \$ 0,68$ & $1,53 \%$ & $3,73 \%$ \\
\hline Leitura & $\mathrm{R} \$ 5,64$ & $13,19 \%$ & $29,00 \%$ & $\mathrm{R} \$ 5,19$ & $9,84 \%$ & $25,80 \%$ \\
\hline Artesanato & $\mathrm{R} \$ 0,54$ & $1,18 \%$ & $13,15 \%$ & $\mathrm{R} \$ 0,70$ & $1,06 \%$ & $9,31 \%$ \\
\hline Espetáculos & $\mathrm{R} \$ 0,74$ & $1,54 \%$ & $3,59 \%$ & $\mathrm{R} \$ 0,89$ & $1,68 \%$ & $3,57 \%$ \\
\hline Indiretos & $\mathrm{R} \$ 14,63$ & $35,24 \%$ & $33,91 \%$ & $\mathrm{R} \$ 22,88$ & $50,62 \%$ & $40,08 \%$ \\
\hline Cursos de artes & $\mathrm{R} \$ 0,50$ & $1,26 \%$ & $2,32 \%$ & $R \$ 0,34$ & $0,84 \%$ & $1,67 \%$ \\
\hline Instrumentos musicais & $\mathrm{R} \$ 0,75$ & $1,94 \%$ & $3,25 \%$ & $\mathrm{R} \$ 0,60$ & $1,35 \%$ & $3,28 \%$ \\
\hline Festas e outras saídas & $\mathrm{R} \$ 4,85$ & $12,83 \%$ & $18,31 \%$ & $\mathrm{R} \$ 4,22$ & $9,47 \%$ & $12,04 \%$ \\
\hline Informática & $\mathrm{R} \$ 8,54$ & $19,21 \%$ & $19,86 \%$ & $\mathrm{R} \$ 17,72$ & $39,09 \%$ & $33,12 \%$ \\
\hline Artigos de inform. & $\mathrm{R} \$ 7,24$ & $16,23 \%$ & $17,08 \%$ & $\mathrm{R} \$ 6,24$ & $13,79 \%$ & $16,10 \%$ \\
\hline Serv. Internet & $\mathrm{R} \$ 1,30$ & $2,99 \%$ & $5,21 \%$ & $\mathrm{R} \$ 11,48$ & $25,27 \%$ & $24,98 \%$ \\
\hline Total no domicílio & $\mathrm{R} \$ 33,02$ & $80,10 \%$ & $70,07 \%$ & $\mathrm{R} \$ 40,02$ & $85,19 \%$ & $71,93 \%$ \\
\hline Diretos no dom. & $\mathrm{R} \$ 23,24$ & $57,59 \%$ & $67,12 \%$ & $\mathrm{R} \$ 21,35$ & $43,62 \%$ & $64,91 \%$ \\
\hline Total fora do dom. & $\mathrm{R} \$ 7,91$ & $19,90 \%$ & $29,63 \%$ & $\mathrm{R} \$ 6,93$ & $15,10 \%$ & $23,74 \%$ \\
\hline Diretos fora do dom. & $\mathrm{R} \$ 3,07$ & $7,07 \%$ & $17,96 \%$ & $\mathrm{R} \$ 2,71$ & $5,60 \%$ & $15,59 \%$ \\
\hline
\end{tabular}

Fonte: IBGE/POF (2002-2003; 2008-2009). Microdados. 
Figura 1 Percentual de domicílios com acesso a telefonia, microcomputador e internet $^{(a)} \mathrm{e}$ indicadores de consumo de serviços de comunicação(b) e cinema $^{(\mathrm{c})}$ Brasil, 2003-2009
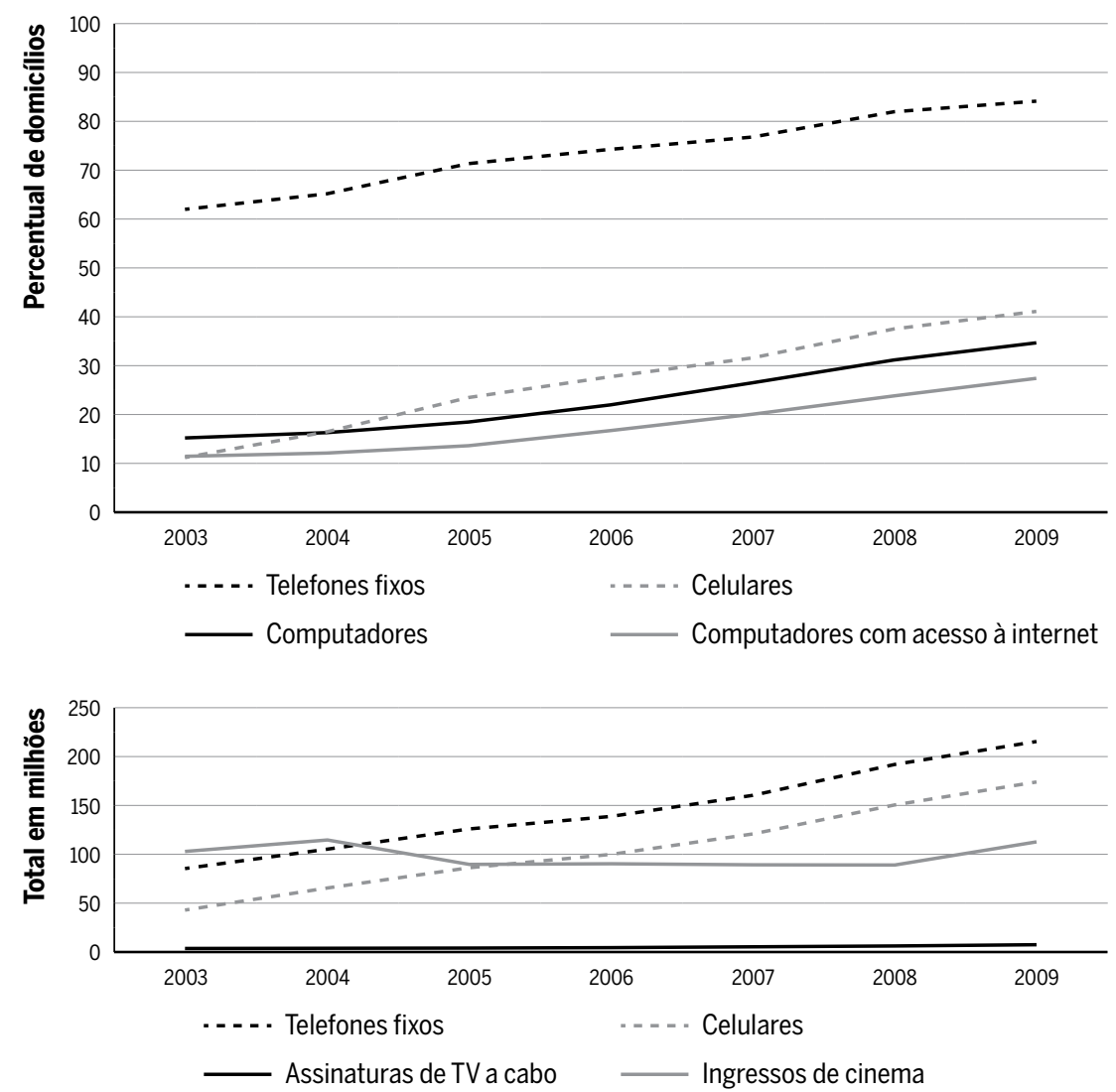

Fonte: (a) IBGE/PNAD; (b) ANATEL; (c)ANCINE.

Embora não compreenda o período de análise deste estudo, os dados mais recentes mostram que a demanda permanece aquecida para esses bens e serviços. Segundo a Anatel (2020), havia no Brasil 226,7 milhões de linhas móveis em operação em dezembro de 2019, 33,5 milhões de telefo nes fixos em serviço; 15,8 milhões de acessos em TV por assinatura e 32,6 milhões de acessos em banda larga fixa. $\bigcirc$ relatório também mostra que telefonia fixa e TVs por assinatura têm apresentado tendência de queda, enquanto a banda larga fixa é o segmento com maior tendência de crescimento, visto que está presente em apenas 46,8\% dos domicílios. Note-se 
que em 2018, cerca de 70\% dos brasileiros tinham acesso à internet, predominante via telefonia móvel, sendo que nas classes $\mathrm{D}$ e $\mathrm{E}$ o acesso atingia 48\% (42\% em 2017), havendo ainda, portanto, bastante espaço para o crescimento do acesso pelas famílias de menor renda. ${ }^{17}$

Cabe ressaltar que a principal limitação dos dados é que os gastos não são uma proxy confiável de consumo para determinados itens de despesa. A variação dos gastos pode ocorrer por diversas razões: a) variação nos preços relativos - então um gasto menor não significa necessariamente redução no consumo por determinado bem ou serviço; b) possibilidade de deslocamento para consumo gratuito. No caso da informática e de serviços com TV por assinatura, o aumento dos gastos familiares reflete crescimento no consumo, pois os preços apresentaram queda no período (Rappa; Maranhão; Reis; Leandro, 2016; Anatel, 2019).

Paralelamente, não se pode afirmar que a redução dos gastos com leitura e fonografia, itens de peso também expressivo, bem como a estabilidade dos gastos com vídeo, significa consumo inferior/estável desses bens. Mesmo os dados sobre vendas de livros, CDS e DVDS não refletem o consumo real, tendo em vista a impossibilidade de mensurar tais práticas realizadas na forma digital, inclusive gratuitamente. Além disso, há uma tendência crescente no número de pessoas que compram produtos piratas no país (Fecomercio/RJ, 2010).

Todos esses fatores contribuíram para queda acentuada tanto dos gastos per capita com som - que engloba aquisição e consertos de aparelhos, além de reprodução de material gravado - quanto da participação no total e do percentual de domicílios que realizam essas despesas. As inovações tecnológicas, particularmente, o MP3 e a banda larga, permitiram ampla difusão dos arquivos musicais, aproximando-se dos "bens livres" e impossibilitando a mensuração do consumo através das estatísticas de gastos e vendas. O reflexo das transformações no mercado fonográfico é visto na queda das vendas do volume físico desses bens, ao mesmo tempo que proporcionou o surgimento de novas fontes de receitas: em 2009, 11,9\% das receitas do setor provieram do mercado digital, subdivido em $58,7 \%$ da internet e 41,3\% da telefonia móvel (ABPD, 2009).

17 Dados da Pesquisa TIC Domicilios estão disponíveis em: <https://g1.globo.com/economia/tecnologia/noticia/2019/08/28/uso-da-internet-no-brasil-cresce-e-70percent-da-populacao-esta-conectada.ghtml>. 
Em meio a essas transformações, alterou-se a proporção de despesas dentro e fora do domicílio a favor das de dentro do domicílio. Em 2008-2009, a proporção gasta fora dos domicílios correspondeu a apenas $15,10 \%$ do total gasto em cultura, sendo que os gastos diretos (cinema e espetáculos e artes) são apenas 1/3 desse valor e foram praticados por $15,59 \%$ das famílias. O cinema respondeu por 3,94\% do total do dispêndio cultural, enquanto os espetáculos, que englobam principalmente idas a teatros, óperas, circos e museus, representaram apenas 1,68\%. Cabe destacar que, no caso dos filmes, a baixa taxa de crescimento dos ingressos vendidos no período analisado não ocorreu por alteração no gosto por filmes (Figura 1), mas porque alternativas domésticas reduziram custos de transação, já que a ida ao cinema acarreta outros gastos e questões de mobilidade (Earp, 2009).

\subsection{Desigualdade das despesas com bens culturais segundo classe de renda}

Os perfis de consumo cultural diferenciam-se substancialmente entre as classes de renda nas RMs brasileiras. A Tabela 2 demonstra que, na classe baixa, $65,89 \%$ das famílias realizaram dispêndios com cultura em 20082009 , enquanto na classe média esse percentual é de $73,27 \%$, e na alta, de 85,51\%. Comparando com 2002-2003, mais domicílios de baixa renda gastaram com cultura, o que não ocorreu nas outras duas faixas, embora a despesa domiciliar média per capita mensal mantenha-se substancialmente inferior, igual a $\mathrm{R} \$ 8,98$, contra $\mathrm{R} \$ 129,67$ per capita mensal da faixa de renda alta.

Ao analisar por grupos de bens e serviços culturais, tem-se que todas as classes de renda reduziram dispêndios médios com bens diretos, ao mesmo tempo em que houve acentuado aumento nos gastos indiretos e no percentual de famílias que realizam esses gastos, em sintonia com as mudanças tecnológicas já citadas. Contudo, o valor médio mensal per capita das famílias de baixa renda, $\mathrm{R}$ \$,56 manteve-se substancialmente inferior aos das faixas das rendas média ( $\mathrm{R} \$ 12,03)$ e alta ( $\mathrm{R}$ 63,93).

Como reflexo do aumento nos gastos indiretos, majoritariamente realizados dentro do domić́lio, nas três classes de renda um menor número relativo de famílias declarou ter despendido fora do domicílio em 2008- 
2009. Nesse caso, também se observa acentuada disparidade nas despesas fora do domicílio, realizadas por somente $11,95 \%$ das famílias de menor poder aquisitivo, cuja média per capita mensal foi de $\mathrm{R} \$ 1,29$. Nas classes média e alta, a proporção de domicílios com esses gastos foi de $20,48 \%$ e $42,07 \%$, respectivamente. Esse resultado é esperado, pois o lazer fora do domicílio envolve outros gastos, inclusive de locomoção na cidade (Silva; Araújo; Souza, 2007), sendo mais viável para famílias de maior renda.

Tabela 2 Despesas culturais domiciliares mensais per capita por faixa de renda segundo POFs 2002-2003 e 2008-2009 - RMs

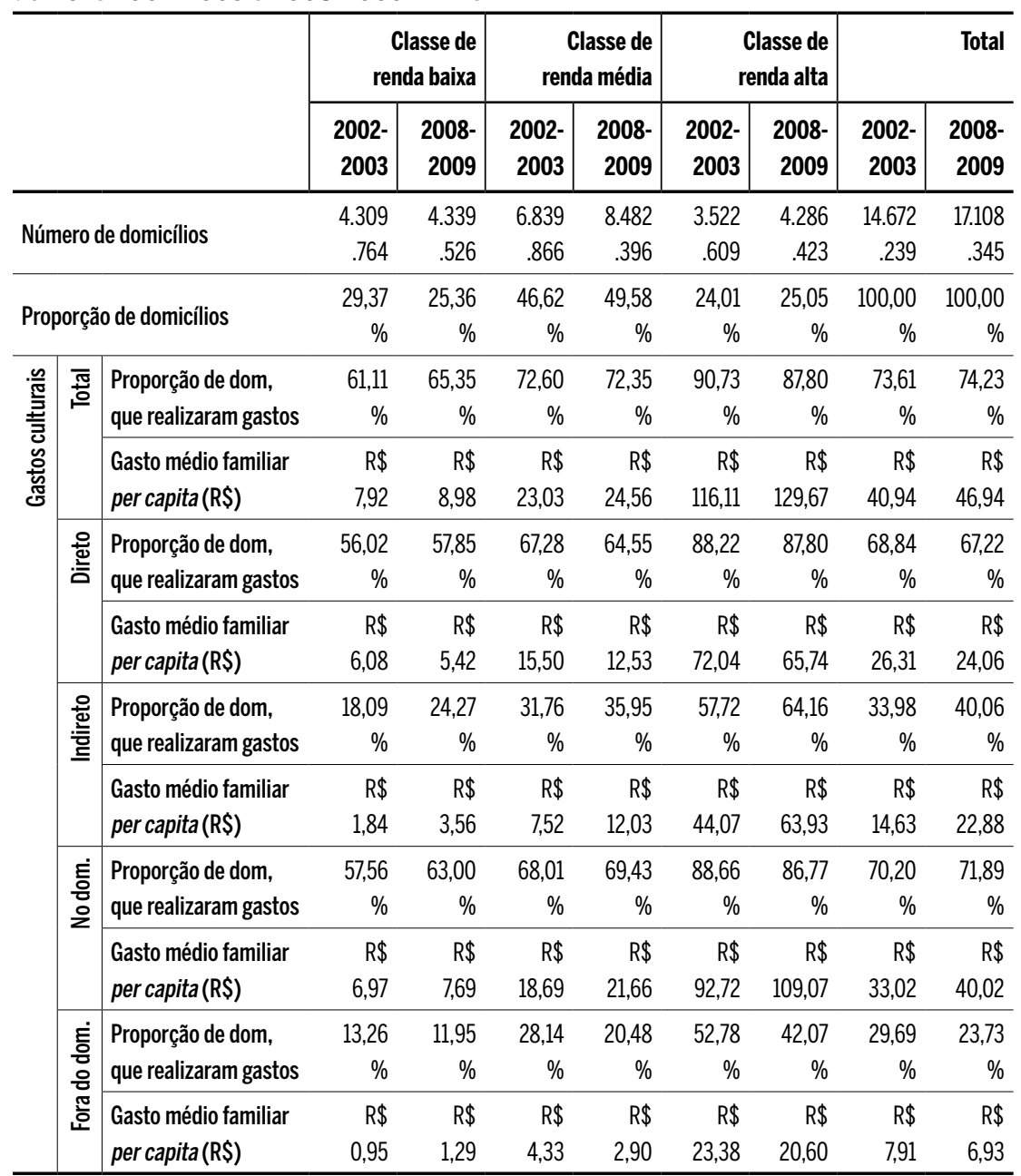

Fonte: IBGE/POF (2002-2003; 2008-2009). Microdados. 
Como já explicitado, fatores não monetários influenciam a propensão a gastar, justificando o fato de as preferências se diferenciarem entre grupos dentro da mesma faixa de renda: os gastos culturais mensais per capita são acentuadamente superiores para os domicílios cujos chefes e/ou cônjuges têm nível superior completo ou incompleto, conforme a Figura 2. Nas classes média e alta, o gasto familiar per capita das famílias com maior nível educacional é o dobro, enquanto na classe de renda baixa é cerca de quatro vezes maior.

Há diferença também nos tipos de bens consumidos, sendo que as maiores discrepâncias se referem aos gastos com leitura: em 2002-2003, famílias com maior nível educacional e pertencentes à classe média gastaram $16,01 \%$ do total despendido com cultura em itens de leitura, contra 10,28\% do caso contrário. Na classe baixa, em 2008-2009, esse percentual foi de $18,68 \%$ e $7,6 \%$, respectivamente. Em segundo lugar, destacam-se as despesas fora do domicílio, com indícios de que a educação influencia positivamente as preferências da classe baixa por saídas culturais (espetáculos).

Figura 2 (a)Despesa cultural domiciliar média mensal per capita ( $R \$) \mathrm{e}^{(\mathrm{b})}$ participação dos itens de despesas culturais no consumo cultural total por classe de renda e nível educacional (\%) segundo POFs 2002-2003 e 2008-2009 - RMs
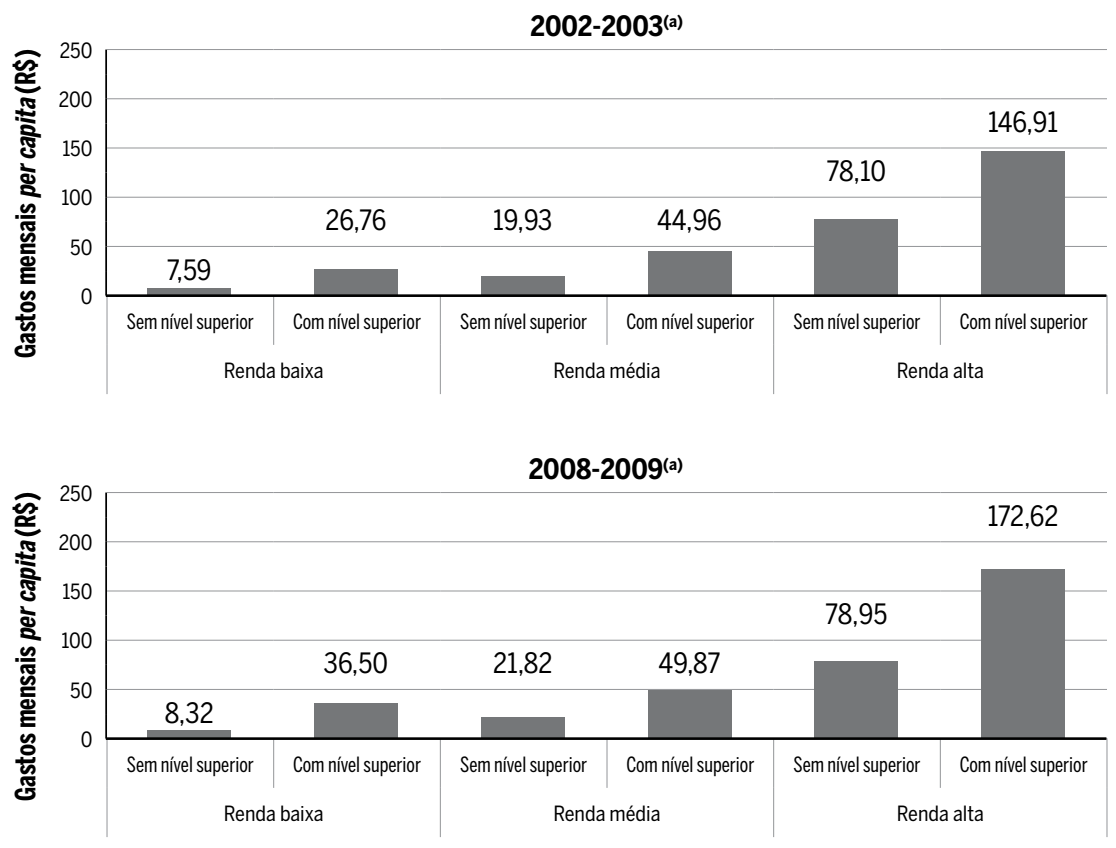


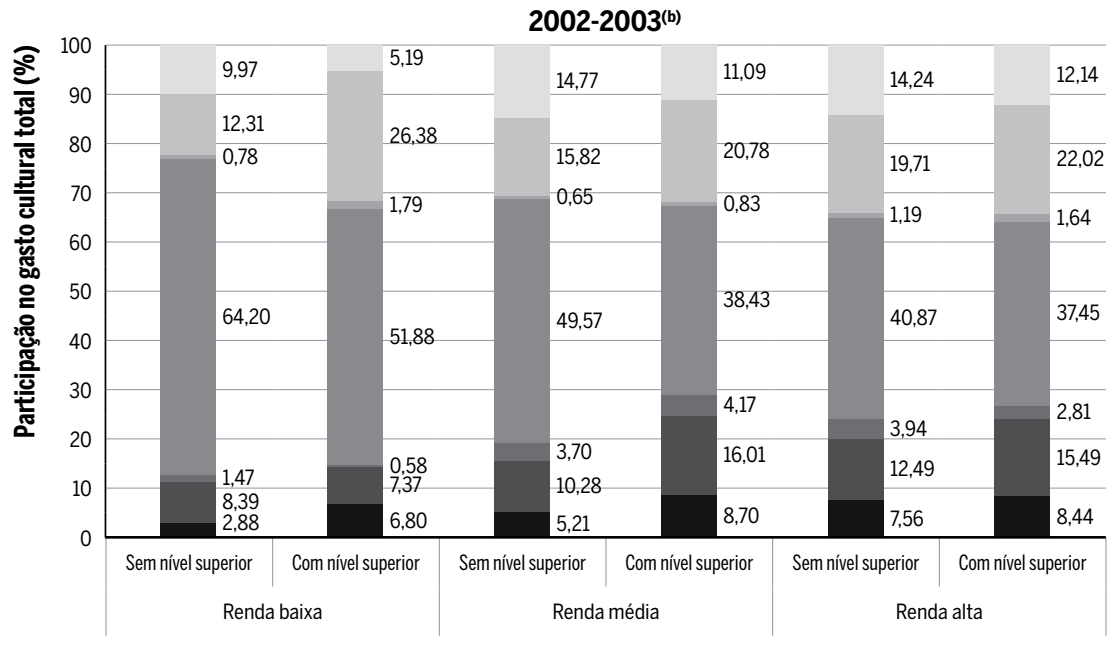

2008-2009(b)

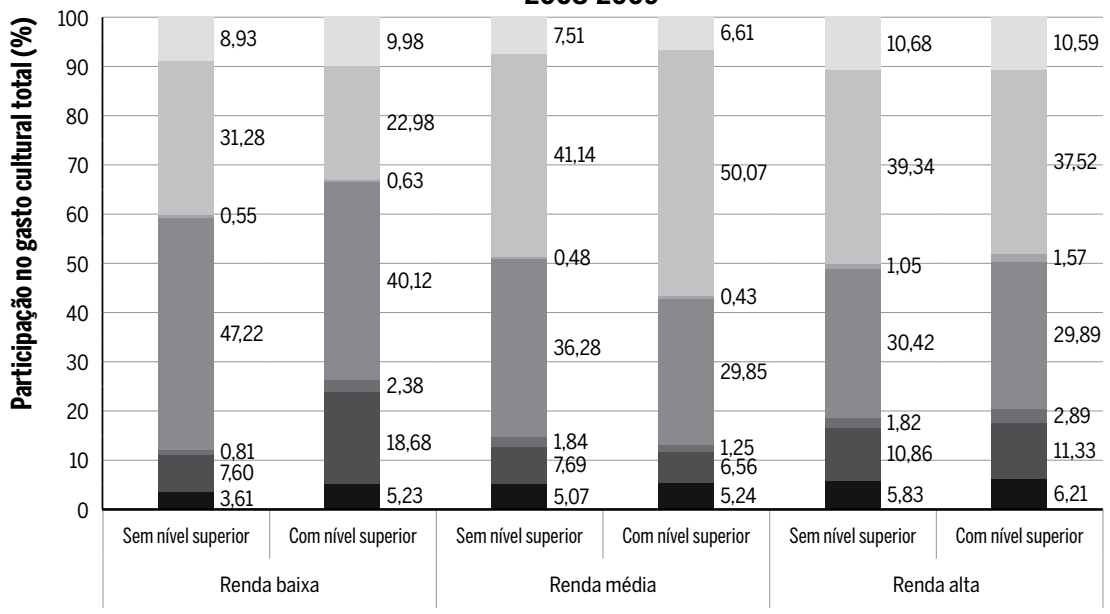
$\square$ Espetáculos
$\square$ Leitura
$\square$ Instru._cursos
Audiov. no dom.
Artesanato
Informática

\section{Festas}

Fonte: IBGE/POF (2002-2003; 2008-2009). Microdados.

Nota: Sem nível superior = famílias em que chefe e/ou cônjuge não possui nível superior; Com nível superior $==$ chefe e/ou cônjuge possui nível superior completo e/ou incompleto.

$\bigcirc$ audiovisual no domicílio foi o principal gasto em todas as classes e níveis educacionais em 2002-2003, enquanto em 2008-2009 informática passa a deter o maior percentual dos dispêndios das classes média e alta para famílias de 
qualquer nível superior. Apesar da forte expansão recente, a TV paga estava presente, no primeiro trimestre de 2009 , em apenas $13 \%$ dos lares, com a maioria dos clientes pertencentes a classes A e B (Lee, 2009). Assim, tem-se a "universalidade [apenas] da televisão como forma de acesso a informações e fonte de entretenimento" (Silva; Araújo; Souza, 2007, p. 128). Aos consumidores de maior renda, através de serviços diversos de vídeo e áudio oferecidos por assinatura, aumenta-se a quantidade e diversidade de conteúdo da programação oferecida, inclusive através de novas tecnologias que permitem a individualização do consumo, por meio dos serviços como streaming (Lee, 2009).

A Tabela 3 demonstra a evolução do índice de Gini, segundo grupo de despesa, para as diferentes classes de rendimento. Uma comparação entre as classes revela que a concentração intraclasse aumenta conforme reduz-se o poder aquisitivo, porém, no período analisado, a classe de renda baixa foi a única que apresentou queda estatisticamente significante no Gini de despesa cultural total.

Esse resultado pode estar relacionado às transformações econômicas e tecnológicas que vêm ocorrendo desde os anos de 1990. Silveira Neto e Menezes (2010) verificaram que a desconcentração do consumo em geral ocorreu a favor das classes menos favorecidas, ao mesmo tempo que as despesas com cultura e recreação estão entre os itens de consumo que contribuíram para a significativa queda na desigualdade de gastos nas RMs entre as POFs 1995-1996 e 2002-2003.

Cabe ressaltar que o coeficiente de Gini dos gastos indiretos - vinculados aos gastos com artigos de informática e serviços de TV e internet - reduziu em todas as classes de renda. Assim, embora não tenha ocorrido mudança no grau de concentração dos gastos culturais totais das RMs, alterou-se o peso com que cada um dos itens de despesas contribuiu para o coeficiente mensurado, o que pode ser verificado através da decomposição da variação do índice de Gini.

Sabe-se que a alteração nos índices de desigualdade pode ocorrer pelos seguintes motivos: aumento ou redução no montante gasto com determinado bem por uma parcela da população e/ou alteração da participação de determinada despesa no total do montante despendido. Para averiguar como esses comportamentos afetaram o índice geral, isto é, quais itens de cultura contribuíram para a (des)concentração do consumo, a Tabela 4 apresenta a decomposição da variação do índice de Gini para os gastos culturais das RMs por item de despesa. 


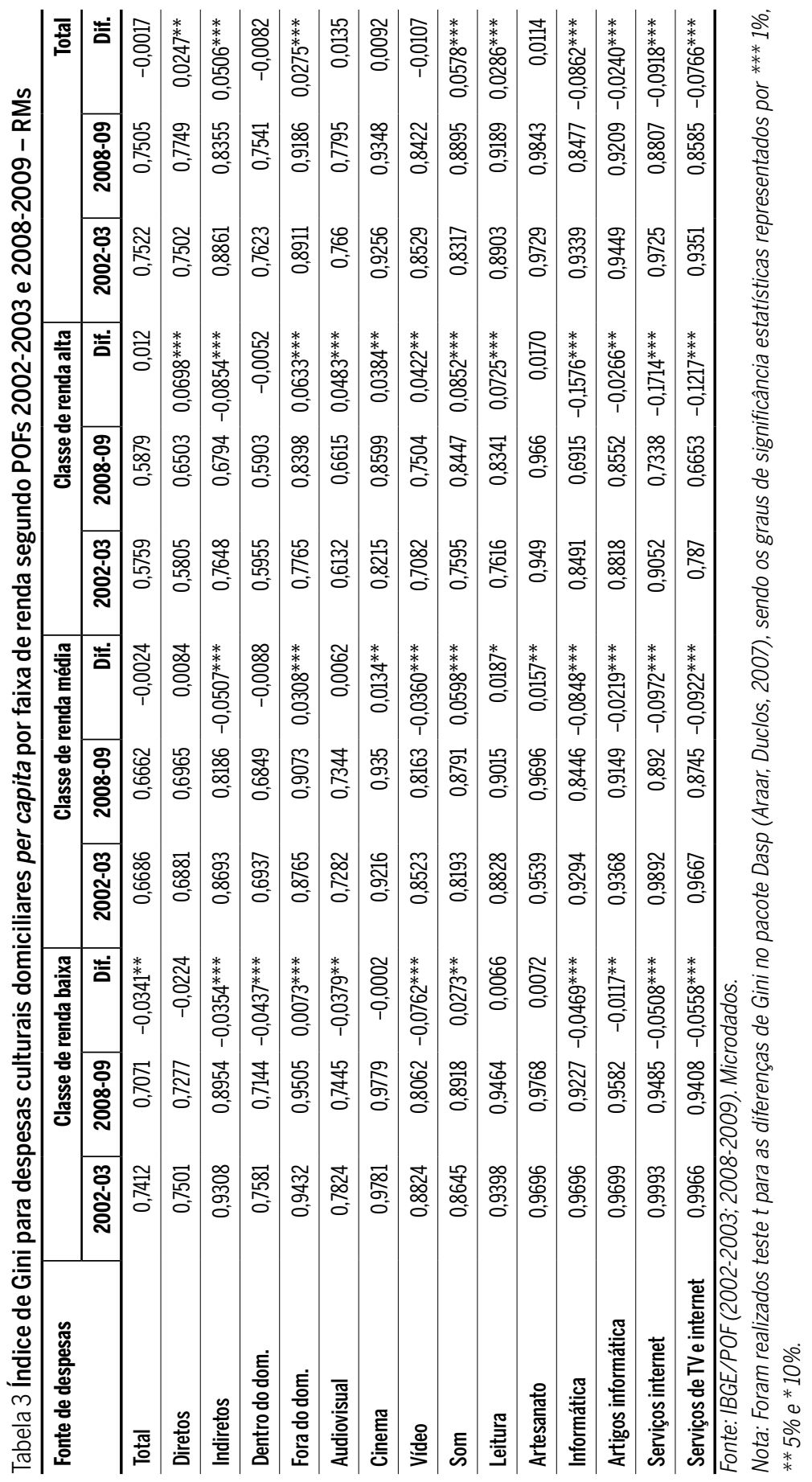


Tabela 4 Decomposição da variação do índice de Gini $(\Delta \mathrm{G})$ para a distribuição das despesas per capita com consumo cultural do total de domicílios, segundo POFs 2002-2003 e 2008-2009 - RMs

\begin{tabular}{|c|c|c|c|c|c|c|c|}
\hline \multirow[t]{2}{*}{ Fonte de despesas } & \multicolumn{2}{|c|}{$\begin{array}{r}\text { Participação no } \\
\text { total (Sh) }\end{array}$} & \multicolumn{2}{|c|}{$\begin{array}{r}\text { Coeficiente de } \\
\text { concentração (Ch) }\end{array}$} & \multirow{2}{*}{$\begin{array}{r}\text { Efeito } \\
\text { partici- } \\
\text { pação } \\
\text { (\%) }\end{array}$} & \multirow{2}{*}{$\begin{array}{r}\text { Efeito } \\
\text { concen- } \\
\text { tração } \\
(\%)\end{array}$} & \multirow{2}{*}{$\begin{array}{r}\text { Efeito } \\
\text { total } \\
(\%)\end{array}$} \\
\hline & $\begin{array}{r}2002- \\
2003\end{array}$ & $\begin{array}{r}2008- \\
2009\end{array}$ & $\begin{array}{r}2002- \\
2003\end{array}$ & $\begin{array}{r}2008- \\
2009\end{array}$ & & & \\
\hline Espetáculos & 0,0182 & 0,0189 & 0,8260 & 0,8157 & $-3,01$ & 11,36 & 8,34 \\
\hline Cinema & 0,0567 & 0,0388 & 0,7674 & 0,7237 & $-6,15$ & 123,78 & 117,63 \\
\hline Artigos de vídeo & 0,1501 & 0,1485 & 0,6583 & 0,6288 & $-10,11$ & 261,45 & 251,33 \\
\hline Serv. de TV & 0,1022 & 0,0956 & 0,8419 & 0,8126 & 29,91 & 171,57 & 201,49 \\
\hline Artigos de som & 0,1641 & 0,0708 & 0,6442 & 0,6340 & $-620,70$ & 70,59 & $-550,11$ \\
\hline Fotografia & 0,0004 & 0,0145 & 0,8761 & 0,7396 & $-47,51$ & 60,29 & 12,78 \\
\hline Leitura & 0,1378 & 0,1105 & 0,7385 & 0,7643 & 0,07 & $-189,61$ & $-189,54$ \\
\hline Artesan., decor. e artes plásticas & 0,0131 & 0,0148 & 0,7278 & 0,8447 & $-3,56$ & $-96,88$ & $-100,44$ \\
\hline Curso de artes & 0,0121 & 0,0073 & 0,8250 & 0,8706 & 27,30 & $-26,31$ & 1,00 \\
\hline Instrumentos musicais & 0,0182 & 0,0128 & 0,7819 & 0,7751 & 8,63 & 6,26 & 14,89 \\
\hline Artigos de informática & 0,1770 & 0,1328 & 0,8456 & 0,7732 & 151,87 & 665,20 & 817,07 \\
\hline Serv. de internet & 0,0317 & 0,2446 & 0,8575 & 0,7836 & $-873,62$ & 605,37 & $-268,25$ \\
\hline Festas e outras saídas & 0,1184 & 0,0898 & 0,7633 & 0,8077 & 57,92 & $-274,15$ & $-216,23$ \\
\hline Total & 1,0000 & 1,0000 & 0,7522 & 0,7505 & $-1.288,95$ & $1.388,91$ & 100,00 \\
\hline
\end{tabular}

Fonte: IBGE/POF (2002-2003; 2008-2009). Microdados.

Nota: $\Delta G=0,0017$. Sh e Ch obtidos por Rao's Approach (RAO, 1969), com variância estimada através de linearização. Método de decomposição conforme procedimento de Hoffmann (2006) com uso do pacote Distributive Analysis Stata Package (DASP), de Araar e Duclos (2007).

Os dados apresentados indicam que os bens e serviços ligados às TICs podem estar contribuindo para a desconcentração dos gastos. Nesse sentido, "Artigos de informática" foi o item de despesa que mais contribuiu para a queda do coeficiente, com percentual de $817 \%$. Ambos os efeitos, participação e concentração, foram favoráveis à queda. Como o índice de concentração é alto, uma queda na participação do total desses gastos contribuiu para redução da desigualdade, mas a maior contribuição ocorreu devido à redução da concentração, cujo efeito é mais do que quatro vezes superior. Esse resultado deve-se tanto à queda de preços desses produtos, como da difusão do consumo entre as famílias. 
Diferentemente do esperado, o item serviços de internet teve efeito contrário: o aumento na participação relativa desses gastos favoreceu a concentração, dado o alto coeficiente de concentração, enquanto a redução na concentração operou em sentido oposto, resultando na contribuição de $216 \%$ para o aumento do Gini. Esse resultado indica que, embora tenha aumentado o acesso às TICs, a alta concentração dos dispêndios com internet pode ser um obstáculo para a inclusão digital e, consequentemente, para a democratização cultural.

Na segunda posição, os itens que mais contribuíram para a queda do Gini foram os pertencentes ao audiovisual, em especial, os serviços de TV. Sua participação nos gastos totais manteve-se praticamente constante, ao mesmo tempo que o coeficiente de concentração diminuiu significativamente. Já nos casos de cinema e artigos de vídeo, o efeito participação foi favorável ao aumento do Gini, mas o efeito concentração, predominante, contribuiu para a redução de desigualdade. Instrumentos musicais, fotografia, espetáculos de cursos de artes também contribuíram para a sua redução, mas em modesta magnitude, já que a participação nos gastos totais desses itens de despesa é baixa.

Os resultados para o Brasil metropolitano divergem dos observados na Espanha por Fernández, Maldonado e Luque (2008), sobretudo quanto aos gastos com leitura, visto que imprensa, sobretudo publicações periódicas, é o bem mais bem distribuído entre as famílias espanholas. Estes, juntamente com livros e jogos de azar, também foram os bens que mais contribuíram para a redução do índice de Gini daquele país em 2003. Nas RMs brasileiras, houve elevação no índice de concentração de leitura, passando de 0,7385 em 2002-2003 para 0,7643 em 2008-2009, contribuindo com o aumento do coeficiente de Gini em -189,54\%.

Por fim, não se observou alteração estatisticamente significante do índice de Gini cultural para o conjunto das RMs. Porém, confirma-se a hipótese de que houve aumento do acesso a bens tecnológicos para as famílias de todas as classes, sobretudo no caso dos itens "artigos de vídeo", "serviços de TV" e "artigos de informática" (Tabela 4). Concomitantemente, as famílias com menor poder aquisitivo foram as mais beneficiadas pelas transformações tecnológicas, o que pode ser visto tanto devido à redução da concentração de gastos intraclasse (Tabela 3) quanto pelo aumento no percentual de famílias que passaram a declarar dispêndios. 


\section{Conclusões}

Na primeira década dos anos 2000, observaram-se no Brasil mudanças nas preferências relacionadas aos bens e serviços culturais, tendo contribuído para isso tanto o aumento da renda quanto as novas possibilidades de oferta, tais como surgimento de produtos substitutos e alteração nos preços relativos, devido às novas TICs. Tendo em vista a proposta de analisar a evolução dos gastos culturais domiciliares nos anos 2000 nas principais RMs brasileiras, as principais evidências deste estudo foram: a) confirma-se o deslocamento de demanda para consumo no domicílio, acompanhado tanto do aumento da participação relativa desses gastos como do maior número de famílias consumidoras; b) significativo aumento do consumo das novas TICs; c) queda no coeficiente de concentração da maioria dos produtos, mas não o suficiente para impactar o índice de Gini cultural, mantendo a alta concentração dos gastos, com diferenciação por grupos de diferentes níveis de renda e educação, e d) redução das desigualdades dos gastos das famílias de classe mais baixa.

A distribuição desigual dos gastos culturais entre as diversas classes de renda e nível educacional dificulta avanços para uma democratização cultural, visto que a melhoria da distribuição de renda ocorrida a partir do ano 2000 não garantiu a incorporação dos hábitos das camadas que já eram superiores, pois a oferta não garante habilidades para apropriação, utilização e criação dos conteúdos. Logo, apesar da contribuição das novas tecnologias para redução das desigualdades, não houve universalização do acesso à banda larga, por exemplo, reduzindo oportunidades de acesso à cultura e informação por meio digital.

Por outro lado, a piora na distribuição de renda observada após 2014 poderá acentuar a concentração dos gastos em cultura, mesmo que facilidades de acesso à inclusão digital estejam ainda compensando, ou mais do que compensando, a piora na distribuição de renda e o maior nível de desemprego. Sobre isso, vale conferir os dados da POF 2017-2018 para se ter uma noção mais clara da continuidade ou não das tendências aqui observadas.

Em suma, mantêm-se fortes restrições aos meios de acesso à cultura e à comunicação, que reforçam as hierarquias sociais devido à falta de oportunidades de criação de capacidades adaptativas dos setores excluídos e que são necessárias para inserção econômica. Dessa forma, esses resultados reforçam o debate gerado em torno das políticas em prol da democratiza- 
ção da cultura e da inclusão digital, cujos esforços devem considerar, além de políticas para facilitação do acesso a bens culturais e às TICs daqueles excluídos economicamente, os aspectos relacionados às desigualdades históricas brasileiras.

\section{Referências}

ABPD - ASSOCIAÇÃO BRASILEIRA DOS PRODUTORES DE DISCOS. Mercado Brasileiro de Música 2009. Disponível em: <http://abpd.org.br/wp-content/uploads/2015/01/Final_ Publicacao_2009_CB.pdf>. Acesso em: 01 out. 2019.

ALVES, E. P. M.; SOUZA, C. A. C. A economia criativa no Brasil: o capitalismo cultural brasileiro contemporâneo. Latitude, v. 6, n. 2, p. 119-173, 2012.

ANATEL - AGÊNCIA NACIONAL DE TELECOMUNICAÇÕES. Dados. Disponível em: $<$ http://www.anatel.gov.br/dados/>. Acesso em: 10 fev. 2019.

ANATEL - AGÊNCIA NACIONAL DE TELECOMUNICAÇÕES. Relatórios de acompanhamento. Panorama Setorial de Telecomunicações. - Dez./2019. Disponível em: <https:// www.anatel.gov.br/dados/2015-01-12-19-11-52/351-relatorios-de-acompanhamento -2019>. Acesso em: 02 fev. 2020.

ANCINE - AGÊNCIA NACIONAL DE CINEMA. Observatório Brasileiro do Cinema e do Audiovisual. Dados de Mercado. Acesso em: 25 jan. 2019.

ARAAR, A.; DUCLOS, J. DASP: Distributive Analysis Stata Package, PEP, World Bank, UNDP and Université Laval, 2007.

ATECA-AMESTOY, V. Determining heterogeneous behavior for theater attendance. Journal of Cultural Economics, v. 32, n. 2, p. 127-151, 2008.

ATECA-AMESTOY, V. El capital humano como determinante del consumo cultural. Estudios de Economía Aplicada, v. 27, n. 1, p. 89-112, 2009.

ATECA-AMESTOY, V.; GERSTENBLÜTH, M.; MUSSIO, I.; ROSSI, M. How Do Cultural Activities Influence Happiness? Investigating the Relationship between Self-Reported Well-Being and Leisure. Estudios Económicos, v. 31, n. 2, p. 217-234, 2016.

BENHAMOU, F. A economia da cultura. São Paulo: Ateliê Editorial, 2007.

BOLAÑO, C. R. S.; REIS, D. A. Banda larga, cultura e desenvolvimento. Nova Economia, v. 25, n. 2, p. 387-402, 2015.

BOTELHO, I. Os equipamentos culturais na cidade de São Paulo: um desafio para a gestão pública. Espaço e Debates. Revista de Estudos Regionais e Urbanos, n. 23/44, 2003. Disponível em: <http://centrodametropole.fflch.usp.br/sites/centrodametropole.fflch.usp.br/ files/inline-images/espaco_debates.pdf>. Acesso em: 17 fev. 2020.

CANCLINI, N. G. Consumidores e cidadãos. Conflitos multiculturais da globalização. Rio de Janeiro: Editora UFRJ, 1999.

DINIZ, S. C.; MACHADO, A. F. (2011). Analysis of the Consumption of Artistic-Cultural 
Goods and Services in Brazil. Journal of Cultural Economics, v. 35, n. 1, p. 1-18, 2011.

EARP, F. S.; PAULANI, L. M. Mudanças no consumo de bens culturais no Brasil após a estabilização da moeda. Nova Economia, v. 24, n. 3, p. 469-490, 2014.

EARP, F. S. O expectador eventual: notas sobre demanda por cinema no Brasil. Políticas Culturais em Revista, v. 2, n. 1, p. 77-87, 2009.

FECOMERCIO/RJ. Pirataria no Brasil: radiografia do consumo. Núcleo Econômico. Estudos / Análises Econômicas, 2010, nov. 11. Sistema Firjan. Disponível em: <http://www.fecomercio-rj.org.br/publique/media/estudo.pdf>. Acesso em: 20 abr. 2018.

FERNÁNDEZ, J. S.; MALDONADO, J. S.; LUQUE, J. M. Descomposición multidimensional del índice de Gini: una perspectiva de la desigualdad territorial del consumo de bienes y servicios socio culturales. In: Encuentro de Economía Pública: Políticas Públicas y Migración, 15, 2008. Anais... Salamanca, Espanha, 2008.

HOFFMANN, R. Desigualdade da renda e das despesas per capita no Brasil, em 2002-2003 e 2008-2009, e avaliação do grau de progressividade ou regressividade de parcelas da renda familiar. Economia e Sociedade, v. 19, n. 3, p. 647-661, 2010.

HOFFMANN, R. Transferências de renda e a redução da desigualdade no Brasil e cinco regiões entre 1997 e 2004. Revista Econômica, v. 8, n. 1, p. 55-81, 2006.

IBGE - INSTITUTO BRASILEIRO DE GEOGRAFIA E ESTATÍSTICA. Pesquisa Nacional por Amostra de Domicilios (PNAD).

IBGE - INSTITUTO BRASILEIRO DE GEOGRAFIA E ESTATÍSTICA. Pesquisa de Orçamentos Familiares - POF 2008-2009 e 2002-2003. Microdados.

IBGE - INSTITUTO BRASILEIRO DE GEOGRAFIA E ESTATÍSTICA. Pesquisa de Orçamentos Familiares 2008-2009. Despesas, rendimentos e condições de vida. Rio de Janeiro: IBGE, 2010.

LEE, I. Impacto das tecnologias na produção, na distribuição e no consumo culturais. In: REIS, A. C. F.; MARCO, K. (Ed.). Economia da cultura: ideias e vivências. Rio de Janeiro: Publit, 2009.

LEIVA, J. (Ed.). Cultura SP: Hábitos culturais dos paulistas. São Paulo: Tuva Editora, 2014.

MACHADO, A. F.; GOLGHER, A. B.; DINIZ, S.; GAMA, L. C. D. Consumption of cultural goods and services and time allocation in Brazil. Nova Economia, v. 27, n. 1, p. 35-63, 2017. Disponível em: <https://doi.org/10.1590/0103-6351/3115>. Acesso em: 17 fev. 2020.

MACHADO, A. F.; MENEZES, T. A.; DINIZ, S. C. Perfil os consumidores de cinema no Brasil Metropolitano. Revista Brasileira de Estudos Regionais e Urbanos, v. 5, n. 1, p. 33-43, 2011.

MANTECÓN, A. R. Consumos culturales y ciudadanía en tiempos de globalización. Indicadores Culturales. Buenos Aires, Argentina: Editorial de la Universidad Nacional de Tres de Febrero, 2009. pp. 90-99.

MATTOS, F.; SANTOS, B.; SILVA, L. O. Evolução de alguns indicadores de inclusão digital no Brasil nos primeiros anos do século XXI. Revista Eptic Online, v. 11, n. 2, 2011.

MORAES, J. L. Economia da cultura: a incorporação de Bourdieu. Boletim Informações FIPE, fev. 2010.

MUÑIZ, C.; RODRÍGUEZ, P.; SUÁREZ, M. J. Participation in cultural activities: specification issues. Journal of Cultural Economics, v. 41, n. 1, p. 71-93, 2017. 
PAGLIOTO, B. F; MACHADO, A. F. Perfil dos frequentadores de atividades culturais: o caso nas metrópoles brasileiras. Estudos Econômicos, v. 42, n. 4, p. 701-730, 2012.

PORTO ALEGRE/RS. Usos do tempo livre e práticas culturais dos porto-alegrenses: relatório de pesquisa. Porto Alegre: Observatório da Cultura, 2015.

RAO, V. M. Two decompositions of concentration ratio. Journal of the Royal Statistical Society, Series A (General), p. 418-425, 1969.

RAPPA, B. F.; MARANHÃO, M.; REIS, S.; LEANDRO, T. TV por assinatura no Brasil: aspectos econômicos e estruturais. Observatório Brasileiro do Cinema e do Audiovisual (OCA). Rio de Janeiro: OCA, 2016.

RINGSTAD, V. LOYLAND, K. The demand for books estimated by means of consumer. survey data. Journal of Cultural Economics, v. 30, n. 2, p. 141-155, 2006.

SAE - Secretaria de Assuntos Estratégicos da Presidência da República. Perguntas e respostas sobre a definição da classe média. Brasília: SAE/PR, 2012.

SILVA, F. B.; ARAÚJO, H. E.; SOUZA, A. L. O consumo cultural das famílias brasileiras. In: Silveira, F. G. et al. (Ed.). Gasto e consumo das famílias brasileiras contemporâneas. Brasília: Ipea, 2007.

SILVEIRA NETO, R. S.; MENEZES, T. A. Nível e evolução da desigualdade dos gastos familiares no Brasil: uma análise para as regiões metropolitanas no período 1996 a 2003. Estudos Econômicos, v. 40, n. 2, p. 341-372, 2010.

SOARES, S. S. D. Análise de bem-estar e decomposição por fatores da queda na desigualdade entre 1995 e 2004. Revista Econômica, v. 8, n. 1, p. 83-115, 2006.

STIGLER, G, J.; BECKER, G. S. De gustibus non est disputandum, American Economic Review, v. 67, n. 2, p. 76-90, 1977.

UNESCO - ORGANIZAÇÃO DAS NAÇÕES UNIDAS PARA EDUCAÇÃO, A CIÊNCIA E A CULTURA. TIC para o desenvolvimento sustentável. Recomendações de políticas públicas que garantem direitos. Oficina Regional de Ciencias de la UNESCO para América Latina y el Caribe - UNESCO MONTEVIDEO/Cetic.br: Montevideo, 2019. Disponível em: $<$ https://www.cetic.br/media/docs/publicacoes/8/14582020190716-tic-para-odesenvolvimento-sustentavel.pdf>. Acesso em: 17 fev. 2020.

\section{Sobre os autores}

Carla Cristina Rosa de Almeida - carlalmeidarosa@gmail.com

Universidade Federal de Mato Grosso, Cuiabá, Mato Grosso. ORCID: https://orcid.org/0000-0002-4942-4942.

João Policarpo Rodrigues Lima - jprlima@ufpe.br

Universidade Federal de Pernambuco, Recife, Pernambuco, Brasil.

ORCID: https://orcid.org/0000-0003-1485-0025.

Maria Fernanda Freire Gatto - mariafernandagatto@gmail.com

Universidade Federal de Pernambuco, Recife, Pernambuco, Brasil.

ORCID: https://orcid.org/0000-0001-8283-0304.

\section{Sobre 0 artigo}

Recebido em 01 de dezembro de 2019. Aprovado em 19 de fevereiro de 2020. 